\title{
AHP-Based College Students Aerobics Teaching Method Reformation Development Research
}

\author{
Songtao Wang ${ }^{*}$
}

Institute of Physical Education, Northeast Normal University, Changchun 130024, Jilin, China

\begin{abstract}
On the basis of combining with lots of literatures information and formers' researches, utilize analytic hierarchy process method to make analytic research on aerobics teaching four kinds of methods: basic composition aerobics teaching method, integrated and decomposing model aerobics teaching method, collective and group practice combinative method, the game aerobics teaching method under the impacts of factors influence of the classroom, aerobics students' receiving degrees, aerobics teachers' teaching difficulty, aerobics popular degree in students. It gets that uses integrated and decomposing combinative aerobics teaching method can let teaching efficiency to arrive at optimum; secondly successively is the game aerobics teaching method, basic composition aerobics teaching method and collective and group practice combinative method. The model provides theoretical guidance for aerobics teaching research, it has profound significances in researching aerobics teaching.
\end{abstract}

Keywords: Aerobics; analytic hierarchy process, teaching methods, physiological functions teaching reformation.

\section{INTRODUCTION}

In regular institution of higher learning sports teaching, aerobics course takes important roles, the event is loved by broad females, aerobics teaching reformation is one of Chinese new class reformation advocated new thought, aerobics teaching advocates independent, explorative learning way, comparing to general sports teaching, aerobics teaching not only has general teaching features but also has its own uniqueness, it has strong openness, can adapt to school all students' hobbies, and meanwhile can also effective organize teachers to teach [1-4].

Regarding aerobics aspect research, many scholars have made correlation researches and got certain achievements, such as : Guo Dan had ever put forward aerobics cooperative type teaching mode was through body dynamics, teaching thought, teaching engineering theory, social cohesion in regular institution of higher learning aerobics teaching, cooperative type aerobics teaching mode had important significances in students comprehensive quality promotion, from which it reflected extreme superiority in teamwork, innovation capacity and teacher-student relations [5-7]; Wu WenWen in Chinese aerobics culture development, she proposed that Chinese aerobics were established and developed in the background of cultural globalization background, aerobics education had gradually been concluded as important part in education [8].

The paper just on the basis of above formers researches, targeted at college students' aerobics teaching methods reformation, it makes further research, by applying questionnaire survey, mathematical statistics, AHP and other methods, it makes analysis of aerobics teaching influential factors, finally gets results that conforms to practice that provides theoretical guidance for further researching aerobics teaching reformation plans' researches.

\section{COLLEGE STUDENTS' AEROBICS TEACHING METHODS REFORMATION MODEL}

By consulting China's statistical yearbook, it can get China's major college students situation of interests in aerobics teaching and China's major college students aerobics class attitudes status, corresponding broken line Fig. (1) is as following shows:

For China's major college students' attitudes towards aerobics class, the paper selects 1000 people to make questionnaire survey, draw the obtained result into bar figure, as following Fig. (2) shows:

From above Fig. (2), it is clear that in Chinese college students likability on aerobics, Beijing, Fujian and other places are deeper with respect to Xinjiang and other places, it shows coastal cities prefer to aerobics. However schoolboys and schoolgirls interests and hobbies on aerobics teaching item are also different, for aerobics class attendance attitudes, schoolgirls that like attending aerobics class occupy $81.9 \%$, and schoolboys occupy $78.9 \%$, it is clear, schoolgirls prefer to aerobics with respect to schoolboys. Therefore, in order to let more students to love aerobics and participate in aerobics, find out most suitable Chinese college aerobics teaching mode is one of important problems that by far we confront.

Aerobics teaching mode suffers multiple factors impacts, such as old -fashioned teaching ideals, aerobics field, and aerobics class learning time and so on. The paper establishes analytic hierarchy process model, makes quantization on 


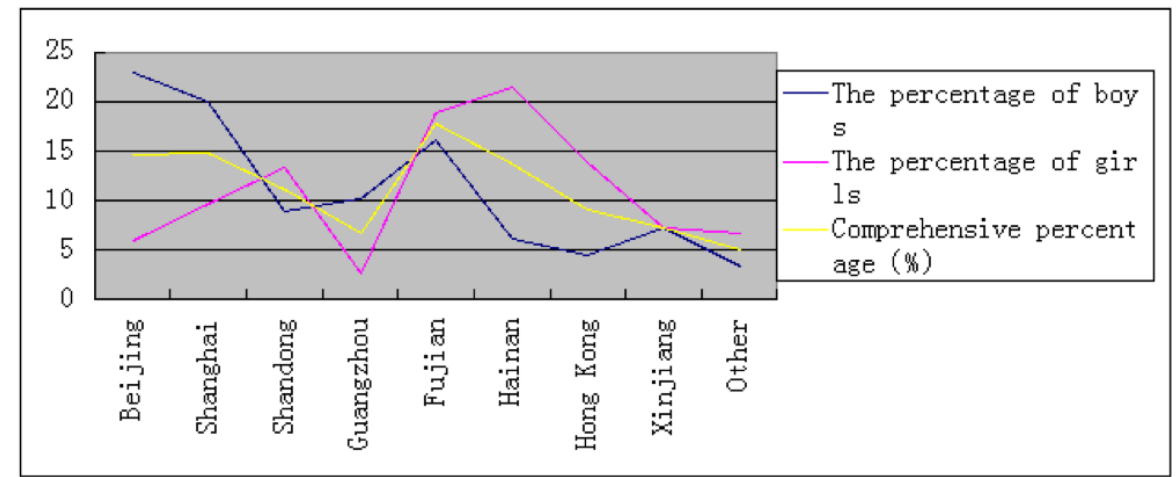

Fig. (1). Students across the country survey of the situation of interest aerobics courses $(\mathrm{N}=863)$.

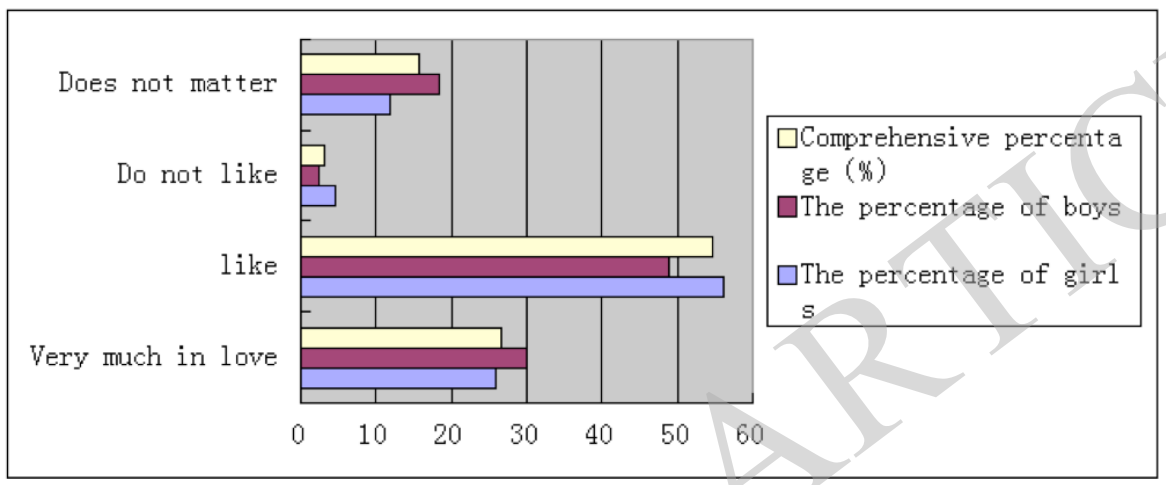

Fig. (2). China's major college students on aerobics class attitude $(\mathrm{N}=1000)$.

Table 1. N pieces of objects weights paired comparison table.

\begin{tabular}{|c|c|c|c|c|}
\hline$T_{1}$ & $\omega_{1} / \omega_{1}$ & $\omega_{1} / \omega_{2}$ & $\mathrm{~L}$ & $\omega_{1} / \omega_{n}$ \\
\hline$T_{2}$ & $\omega_{2} /$ & $\omega_{2} / \omega_{2}$ & $\mathrm{~L}$ & $\omega_{2} / \omega_{n}$ \\
\hline M & $M$ & M & 0 & M \\
\hline
\end{tabular}

aerobics teaching mode orientations, by establishing target layer, criterion layer, and scheme layer relations, finally it gets future most suitable Chinese college aerobics teaching mode.

The paper selects four kinds of teaching ways; they are respectively basic composition aerobics teaching method, integrated and decomposing model aerobics teaching method, collective and group practice combinative method, the game aerobics teaching method. Go ahead with analytic hierarchy process with them, factors that need to consider are aerobics students' receiving degrees, aerobics teachers' teaching difficulty, influence of the classroom, aerobics popular degree in students.

Firstly, use simple examples analysis to illustrate analytic hierarchy process basic principles. If there are $n$ pieces of objects $T_{1}, T_{2}, \cdots, T_{n}$, their corresponding weights are respectively $\omega_{1}, \omega_{2}, \mathrm{~L}, \omega_{n}$. Make mutual comparison, after that, it can get corresponding comparison matrix, corresponding table is as following Table 1 shows: is:

If use matrix to express the mutual weight relations, that

$$
T=\left(\begin{array}{cccc}
\frac{\omega_{1}}{\omega_{1}} & \frac{\omega_{1}}{\omega_{2}} & \cdots & \frac{\omega_{1}}{\omega_{2}} \\
\frac{\omega_{2}}{\omega_{1}} & \frac{\omega_{2}}{\omega_{2}} & \cdots & \frac{\omega_{2}}{\omega_{n}} \\
\vdots & \vdots & \ddots & \vdots \\
\frac{\omega_{n}}{\omega_{1}} & \frac{\omega_{n}}{\omega_{2}} & \cdots & \frac{\omega_{n}}{\omega_{n}}
\end{array}\right)
$$

Then $\mathrm{T}$ is judgment matrix. If assign weight vector $\omega=\left(\begin{array}{llll}\omega_{1} & \omega_{2} & \mathrm{~L} & \omega_{n}\end{array}\right)^{T}$, then it has:

$T_{\omega}=\lambda \omega$ 


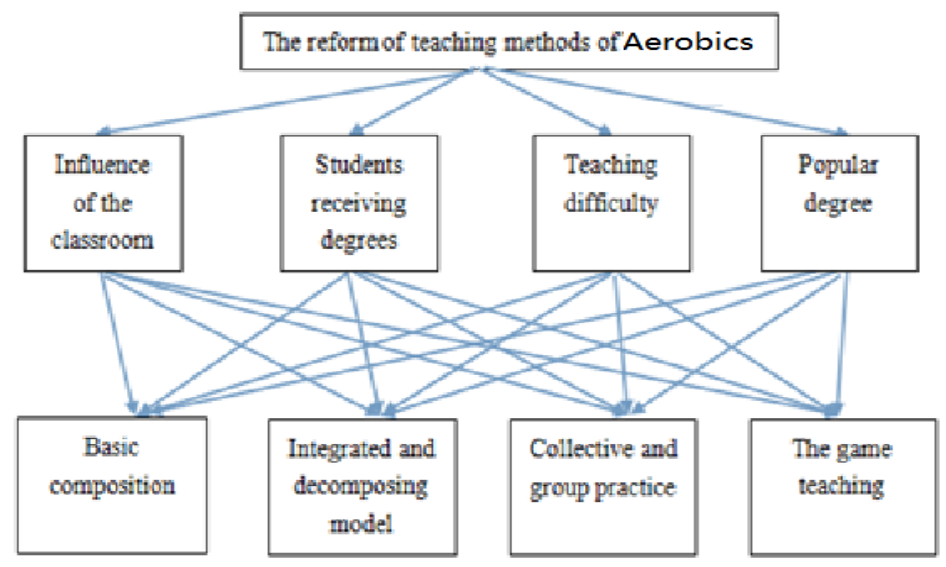

Fig. (3). Hierarchical structure chart.

Table 2. Importance scale definition table.

\begin{tabular}{|c|c|}
\hline Scale $u_{i j}$ & Definition \\
\hline \hline 1 & Indicates two factors have equal importance by comparing \\
\hline 3 & Indicates the former is slightly more important than the later by comparing two factors \\
\hline 5 & Indicates the former is obviously more important than the later by comparing two factors \\
\hline 7 & Indicates the former is intensely more important than the later by comparing two factors \\
\hline $2,4,6,8$ & Indicates the former is extremely more important than the later by comparing two factors \\
\hline Reciprocal & If the former element and later element importance ratio is $u_{i j}$, then later element and former element importance ratio is $u_{i j}=1 / u_{j i}$ \\
\hline
\end{tabular}

Among then, $\omega$ is $T$ feature vector, $\lambda$ is one feature value of $T$. In fact, according to linear algebra knowledge, it is clear that $\lambda$ is matrix $T$ unique non-zero that is maximum feature value, and $\omega$ is its corresponding feature vector, and for such factors that cannot measure, only introduce reasonable scale, it can also use the method to measure each factor relative importance, and then provide relative evidence for relevant decisions.

Analytic hierarchy process model roughly needs following four steps:

- Hierarchical structure establishment;

- Construct every layer that fully used in judgment matrix;

- Hierarchical single arrangement and consistency test;

- Hierarchical total arrangement and consistency test

(1) Hierarchical model establishment

Analytic hierarchy process solved problems are required to be hierarchic, orderly and logic. Only then it can construct hierarchical scheme. Let tedious problems' elements to form into multiple hierarchies according to its attributes, membership and its relations. From which, it mainly contains 3 hierarchies that are respectively:

Target layer (U): The reform of teaching methods of Aerobics.
Criterion layer $(\mathrm{K})$ : scheme influence factors, $K_{1}$ is influence of the classroom, $K_{2}$ is students' receiving degrees, $K_{3}$ is aerobics teachers' teaching difficulty, $K_{4}$ is popular degree.

Scheme layer (T): $T_{1}$ is basic composition aerobics teaching method, $T_{2}$ is integrated and decomposing model aerobics teaching method, $T_{3}$ is collective and group practice combinative method, $T_{4}$ is the game aerobics teaching method.

Hierarchical structure is as Fig. (3).

(2) Construct judgment matrix

According to hierarchical structure, it can construct judgment matrix.

According to linear algebra theoretical knowledge, if matrix $U=\left(u_{i j}\right)_{n \times n}$ meets $u_{i j}>0$ and $u_{j i}=\frac{1}{u_{i j}}(i, j=$ $1,2, \cdots, n)$, then matrix $U$ is positive reciprocal matrix.

Among them, $u_{i j}$ value respectively is expressed by 1 9 scale number and its reciprocal, Saaty thought after researching that used $1 \sim 9$ to express comparison structure, number respectively expressed definition is as following Table 2. 

is:

According to above scale Table 2, set judgment matrix $U$

$U=\left(\begin{array}{cccc}1 & 1 / 6 & 1 / 5 & 3 \\ 6 & 1 & 2 & 4 \\ 5 & 1 / 2 & 1 & 3 \\ 3 & 1 / 4 & 1 / 3 & 1\end{array}\right)$

Combine with the paper's aerobics research, it can get different criterions scheme layers, its result is as following Tables 3-6 shows:

(3) Consistency test

Matrix $U$ corresponding maximum feature value $\lambda_{\max }$ feature vector $W$, it can get corresponding weight by normalization processing. Though the process can reduce other factors interference, it is hard to avoid appearing inconsis- tency to some extent when integrate all comparison results. If comparison results are consistent, then $\mathrm{U}$ factor should also meet:

$u_{i j} u_{j k}=u_{i k}, \forall i, j, k=1,2, \cdots, n$

The positive reciprocal matrix that meets above formula is called consistent matrix. To easy define $U$ can be accepted or not, it should test $U$ inconsistency is very serious or not.

If $U$ is consistent matrix, then $U$ surely is positive reciprocal matrix, transposed matrix $U^{T}$ is consistent matrix, $U$ matrix any two lines are in proportions, and factors are above 0 , therefore $\operatorname{rank}(U)=1$, so is the column, in $U$, $\lambda_{\max }=n, n$ is $U$ matrix order number. Other features

Table 3. K-T judgment matrix one.

\begin{tabular}{|c|c|c|c|c|}
\hline$K_{1}$ & $T_{1}$ & $T_{2}$ & $T_{3}$ & $T_{4}$ \\
\hline \hline$T_{1}$ & 1 & 2 & 3 & 3 \\
\hline$T_{2}$ & $1 / 2$ & 1 & 1 & 4 \\
\hline$T_{3}$ & $1 / 2$ & $1 / 3$ & $1 / 2$ & 1 \\
\hline$T_{4}$ & $1 / 3$ & $1 / 4$ & 3 \\
\hline
\end{tabular}

Table 4. P-C judgment matrix two.

\begin{tabular}{|c|c|c|c|c|}
\hline$K_{2}$ & $T_{1}$ & $T_{2}$ & $T_{3}$ & $T_{4}$ \\
\hline$T_{1}$ & 1 & 2 & 3 & 5 \\
\hline$T_{2}$ & $1 / 2$ & 1 & 2 & 4 \\
\hline$T_{3}$ & $1 / 3$ & $1 / 2$ & 1 & 1 \\
\hline$T_{4}$ & $1 / 5$ & $1 / 4$ & $1 / 3$ & 1 \\
\hline
\end{tabular}

Table 5. P-C judgment matrix three.

\begin{tabular}{|c|c|c|c|c|}
\hline$K_{3}$ & $T_{1}$ & $T_{2}$ & $T_{3}$ & $T_{4}$ \\
\hline$T_{1}$ & 1 & $1 / 2$ & 3 & 3 \\
\hline$T_{2}$ & 2 & 1 & 1 & 2 \\
\hline$T_{3}$ & $1 / 2$ & $1 / 3$ & $1 / 2$ & 1 \\
\hline$T_{4}$ & $1 / 3$ & $1 / 3$ & \\
\hline
\end{tabular}


Table 6. C-P judgment matrix four.

\begin{tabular}{|c|c|c|c|c|}
\hline$K_{4}$ & $T_{1}$ & $T_{2}$ & $T_{3}$ & $T_{4}$ \\
\hline \hline$T_{1}$ & 1 & 3 & $1 / 2$ & 3 \\
\hline$T_{2}$ & $1 / 3$ & 1 & 3 & 3 \\
\hline$T_{3}$ & 2 & $1 / 3$ & 3 & $1 / 3$ \\
\hline$T_{4}$ & $1 / 3$ & $1 / 3$ & 1 & 1 \\
\hline
\end{tabular}

Table 7. Average random consistency indicator R.I. table.

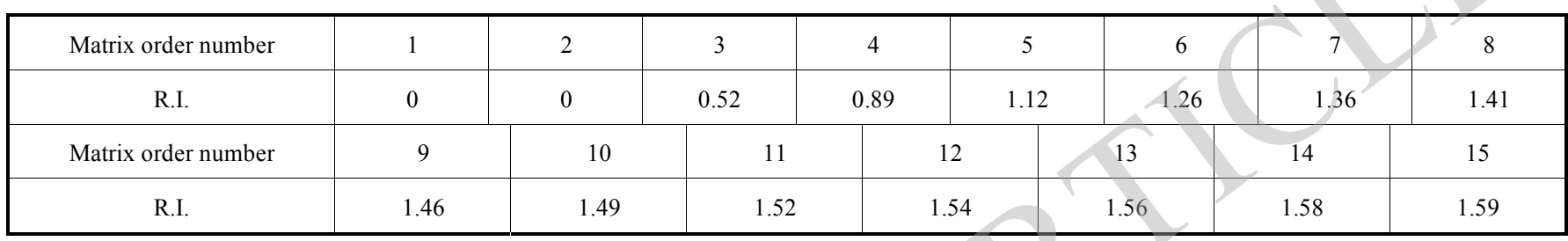

roots of $U$ is $0, \lambda_{\max }$ corresponding feature vector $W=\left(w_{1}, \mathrm{~L}, w_{n}\right)^{T}$, then $u_{i j}=\frac{w_{i}}{w_{j}}, \forall i, j=1,2, \cdots, n$, so:

$$
U=\left(\begin{array}{cccc}
\frac{w_{1}}{w_{1}} & \frac{w_{1}}{w_{2}} & \cdots & \frac{w_{1}}{w_{n}} \\
\frac{w_{2}}{w_{1}} & \frac{w_{2}}{w_{2}} & \cdots & \frac{w_{2}}{w_{n}} \\
\vdots & \vdots & \ddots & \vdots \\
\frac{w_{n}}{w_{1}} & \frac{w_{n}}{w_{2}} & \cdots & \frac{w_{n}}{w_{n}}
\end{array}\right)
$$

$U$ is $n$ order positive reciprocal matrix, when it is consistent matrix, when and only when $\lambda_{\text {max }}=n$ as well as when $U$ is inconsistent, it surely has $\lambda_{\max }>n$. Thereupon, use $\lambda_{\max }$ and $n$ relationship to test whether $U$ is consistent matrix or not.

$U$ consistency test calculation steps:

Firstly, according to data, it can get:

$\lambda_{\max }=\sum_{i=1}^{4} \frac{\left(U \omega_{A}\right)_{i}}{n \omega_{A i}}=4.231$

And go ahead with consistency indicator C.I.calculation,

$$
\text { C.I. }=\frac{\lambda_{\max }-n}{n-1}=\frac{4.2310-4}{4-1}=0.077
$$

Secondly, consult corresponding average random consistency indicator R.I. . RI Value could refer to Table 7:
R.I. Value is got in this way that randomly constructs 1000 sample matrixes. Random select numbers from 1 to 9 as well as its reciprocals to construct positive reciprocal matrix, and determine average value of maximum feature root $\lambda_{\max }^{\prime}$, and define:

$$
R I=\frac{\lambda_{\max }^{\prime}-n}{n-1}=0.89
$$

Finally, solve consistency ratio C.R.

$$
\text { C.R. }=\frac{\text { C.I. }}{\text { R.I. }}=0.0865<0.1
$$

when $C R<0.10$, it is thought that $U$ consistency is acceptable, when $C R>0.10$, it is thought that $U$ consistency cannot pass, it should make adjustment. According to formula (8), consistency passes.

In the process, it also includes hierarchical total arrangement and consistency test, due to article lengths are limited, no theoretical statements here, directly apply it in the following.

\section{(4) Computed result}

The model involved algorithm can implement by Matlab software programming, therefore it can get hierarchical single arrangement and total arrangement computed result as following Table $\mathbf{8}$ shows:

By above Table $\mathbf{8}$, we can get integrated and decomposing combination aerobics teaching method total arrangement weight is the largest, and meanwhile it also gets four kinds of aerobics teaching methods importance degree. Among them, integrated and decomposing combination aerobics teaching method is better. Secondly is the game aerobics teaching method, and then is basic composition aerobics teaching 
Table 8. Hierarchical total arrangement.

\begin{tabular}{|c|c|c|c|c|c|c|}
\hline \multicolumn{2}{|c|}{ Criterion } & $\begin{array}{l}\text { Aerobics Popular } \\
\text { Degree in Students }\end{array}$ & $\begin{array}{l}\text { Aerobics Teach- } \\
\text { ers' Teaching } \\
\text { Difficulty }\end{array}$ & $\begin{array}{l}\text { Influence of the } \\
\text { Classroom }\end{array}$ & $\begin{array}{c}\text { Aerobics Stu- } \\
\text { dents' Receiving } \\
\text { Degrees }\end{array}$ & \multirow[t]{2}{*}{$\begin{array}{c}\text { Total Arrange- } \\
\text { ment Weight }\end{array}$} \\
\hline \multicolumn{2}{|c|}{ Criterion layer weight } & 0.1794 & 0.3606 & 0.1783 & 0.5284 & \\
\hline \multirow{4}{*}{ 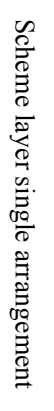 } & $\begin{array}{l}\text { Collective and } \\
\text { group practice }\end{array}$ & 0.1094 & 0.1744 & 0.4322 & 0.3314 & 0.3347 \\
\hline & $\begin{array}{l}\text { Integrated and } \\
\text { decomposing } \\
\text { combination }\end{array}$ & 0.0948 & 0.2758 & 0.5339 & 0.4233 & .4353 \\
\hline & $\begin{array}{l}\text { Basic composi- } \\
\text { tion }\end{array}$ & 0.0785 & 0.1663 & 0.2835 & 0.4740 & \\
\hline & $\begin{array}{l}\text { The game aero- } \\
\text { bics teaching }\end{array}$ & 0.2080 & 0.1199 & 0.5773 & 0.3881 & \\
\hline
\end{tabular}

method, finally is collective and group practice aerobics teaching method.

\section{CONCLUSION}

The paper makes analysis and researches on college students aerobics teaching method reformation, from which it analyzes aerobics basic combination way four kinds of teaching methods, selects aerobics teaching reformation main influence factors are influence of the classroom, aerobics students' receiving degrees, aerobics teachers' teaching difficulty, aerobics popular degree in students, by applying analytic hierarchy process and other methods, it makes analysis, and gets that uses integrated and decomposing combinative aerobics teaching method can let teaching efficiency to arrive at optimum; secondly successively is the game aerobics teaching method, basic composition aerobics teaching method and collective and group practice combinative method. The result basically conforms to investigation practical status; it shows the model rationality and effectiveness, so it has popularization.

\section{CONFLICT OF INTEREST}

The authors confirm that this article content has no conflict of interest.

\section{ACKNOWLEDGEMENTS}

Declared none.

\section{REFERENCES}

[1] P. Ya-Jun, "Shanxi province college aerobics class teaching status and teaching reformation countermeasures research", Shanxi Normal University, 2005.

[2] W. Liang-Qing, "Discuss sports teaching's students cooperative learning and cooperative ability cultivation", Journal of Ningde teachers' training school( Natural science edition), vo. 03, pp. 5-9, 2006.

[3] Z. Jin-Wu, "Application of Matlab in mathematical modeling", Beijing University Of Aeronautics And Astronautics Press, 2010.

[4] S. Min, X. Hong-Jun, "Utilize small group teaching mode to improve aerobics teaching", Journal Of Xi'an University Engineering, vol. 05 , pp. 13-56, 2006

[5] L. Fen, "Economic developed region urban residents sports lifestyle and its value selection-take aerobics audiences as research individual cases", Sports and science, vol. 32, no. 6, pp. 45-54, 2011.

[6] S. Meng, "Shandong province regular institution of higher learning aerobics class status investigation and countermeasures analysis", Shandong Normal University, 2007.

[7] C. Dong-Mei, "Universities aerobics class implementing "team combinative learning" mode research", Journal of Shenyang Normal University (Natural science edition), vol. 04, 2002.

[8] Z. Ying, "Chengdu city universities public sports aerobics class status and countermeasures research:, Sichuan University, 2006.

(C) Songtao Wang; Licensee Bentham Open.

This is an open access article licensed under the terms of the (https://creativecommons.org/licenses/by/4.0/legalcode), which permits unrestricted, noncommercial use, distribution and reproduction in any medium, provided the work is properly cited. 